\title{
ASPECTOS ULTRA-ESTRUTURAIS DA DOENÇA DE PARKINSON
}

\author{
JAMES PITAGORAS DE MATTOS* - ALEXANDRE ALENCAR ** \\ ANGELA GONGALVES DA SILVA *** - MARIA EVANGELINA FERREIRA FONSECA 录**
}

\begin{abstract}
RESUMO - A análise de cinco encéfalos humanos, quatro de pacientes parkinsonianos e um de controle, pela microscopia eletrónica de transmissão, evidenciou as seguintes mais freqüen, tes alteraçōes: empobrecimento de fibras nervosas, grande aumento do espaco intersticial, desinteyracão do neurónilo e tumefação e degeneração das mitocôndrias. Com exceção das alteracōes mitocondriais, as demais ocorreram em todos os encéfalos dos parkinsonianos, fato não observado no caso controle, o que torna difícil atribuí-las à fixação. Traduzem, em última análise, a perda neuronal crônica. Houve, também, presença de depósitos amorfos no interior das mitocôndrias, dos axônios, do citoplasma e do espaço intersticial.
\end{abstract}

Itrastructural aspects of Parkinson's disease.

SUMMARY - Brains from four parkinsonian patients and one control patient were analysed by electron microscopy. The most consistent abnormal findings were nerve fibers rarefaction, great interstitial space enlargement, neuropil disruption, mitochondrial tumefaction and degenerative changes. These findings occurred regularly in the brain of parkinsonian patients. Furthermore, except for mitochondrial changes, they were distinctively absent in the control patient, and therefore cannot be attributed to technical problems. Contrarywise, they clearly reflect chronic neuronal loss. Also noteworthy was the demonstrative of deposits of amorphous substance into mitochondria, axons, cytoplasm and into the interstitial space.

Contrastando com a grande contribuição que a microscopia óptica forneceu aos atuais conhecimentos neuropatológicos sobre a doença de Parkinson, poucos foram os estudos ultra-estruturais realizados até o presente. Isto é compreensivel, pois, com o advento da levodopa, que provocou radical mudança no tratamento medicamentoso, o interesse maior voltou-se para o aperfeiçoamento farmacológico da droga e para a busca incessante de novos medicamentos. Só ultimamente, com a diminuição do entusiasmo terápêutico inicial, as pesquisas parecem mais preocupadas com o obscuro aspecto etiopatogênico. Duffy e Tennyson ${ }^{4}$, em 1965, foram os primeiros a relatar a ultra-estrutura dos corpos de Lewy na substância negra e no 'locưs coeruleus'. Chamaram a atenção para o fato de estes serem compostos por material fibrilar e granular. As fibras arranjam-se frouxa e radiadamente na zona externa e elementos reunidos densamente compõem a parte central. Ressaltaram que, apesar de estudos morfológicos elaborados, a sua origem era ainda desconhecida podendo ser resultado de processo degenerativo único dos neurônios que contêm melanina. Roy e Wolman ${ }^{9}$, em 1969, não encontraram qualquer argumento para inferir a contribuição dos grânulos de melanina na formação dos corpos de Lewy. Nesse mesmo ano, os mesmos autores $\mathbf{9}$ pesquisaram os aspectos uItra-estruturais dos corpos de Lewy, da 'corpora amylacea'

Trabalho realizado no Instituto de Neurologia Deolindo Couto da Universidade Federal do Rio de Janeiro (UFRJ) e no Departamento de Virologia do Instituto de Microbiologia da UFRJ: * Professor Adjunto e Doutor; ** Professor Adjunto e Chefe do Laboratório de Neuropatologia do INDC; *** Técnica de nível superior da FINEP; **** Professor Adjunto de Microbiologia da UFRJ. 
e dos grânulos de melanina na substância negra do mesencéfalo de parkinsonianos. Em relaşăo ao primeiro - corpos de Lewy - confirmaram a composição das inclusōes intraneurais esféricas: material granular e fibrilar. Já no que diz respeito à segunda - ultra-estrutura da 'corpora amylacea' - descreveram suas diferenças com os corpos de Lewy. O terceiro elemento estudado - a fina estrutura dos grânulos de melanina - foi comparado aos dos individuos sem parkinsonismo. Excetuando-se a reduçăo em número daqueles afetados pela doença, não se notou qualquer diferença estrutural pertinente. Em 1976, Forno e Norville 6 examinaram ao microscópio eletrônico o corpo de Lewy no gânglio estrelado em autópsias de 9 pacientes parkinsonianos. Apontaram três principais formas: a) corpos de Lewy com filamentos raros, semelhantes aos do sistema nervoso central; b) corpos de Lewy granulares, nos processos nervosos celulares; c) processos celulares anormais, repletos de material heterogêneo. Watanabe e col.10, em 1977, incidentalmente encontraram corpos de Lewy na autópsia de caso de parkinsonismo, assim como numerosas vesículas coradas e densas, de 80 a $200 \mathrm{~nm}$ de diâmetro, no pericarion do 'locus coeruleus'. Estas eram particularmente numerosas na vizinhança dos corpos de Lewy. Na substância negra, Forno 5 , em 1981, encontrou raros exemplos de fibras muito finas, não mielinizadas, que poderiam representar 'botōes axonais'. No 'locus coeruleus', podem-se observar sinapses axosomáticas nas células nervosas com os corpos de Lewy ou com a degeneração neurofibrilar. Ainda no 'locus coeruleus', encontrou certos depósitos amorfos no interior de mitocôndrias, em cérebros de pessoas de meia idade e idosas, com ou sem parkinsonismo. Descreveu como inclusões não-membranosas, amorfas, preenchendo a matriz mitocondrial. Na oportunidade, os autores suspeitaram ser sua composiçāo de fosfolipídios. Pelo fato de haver, em cada indivíduo, grande variação normal na quantidade de vesiculas nos terminais, Forno e Norville 6 questionaram o acúmulo destas vesículas sinápticas na substância negra de parkinsonianos, pois poderia significar que as vesículas se acumulassem em axônios pré-terminais quando os elementos pós-sinápticos degenerassem.

O presente estudo tem por objetivo analisar as alterações ultra-estruturais em quatro encéfalos de parkinsonianos e, desta forma, contribuir para a melhor compreensão dos seus obscuros fatores etiopatogênicos.

\section{MATERIAL E MĚTODOS}

Em que pese o esforço despendido para reunirmos o maior número possivel de material humano, somente conseguimos quatro encéfalos de pacientes falecidos com a doença de Parkinson e um de controle. Todos procederam do Instituto de Neurologia Declindo Couto da UFRJ, correspondendo às autópsias de números 411,417, 426, 428 e 629. Todos eram do sexo masculino, pertenciam ao grupo étnico branco, apresentavam a forma clínica tremulante e experimentaram a evolução lenta da enfermidade. Contavam com a média de idade de 54 anos, a idade de início da doença tinha ocorrido em média aos 50 anos e 0 tempo de doensa, em média, era de 4 anos. Quanto ao tipo provável de parkinsonisno, três eram idiopáticos e um vascular (caso 3). Os quatro primeiros encéfalos estavam conservados em formal a $10 \%$ há mais de 20 anos.

Para o estudo ultra-estrutural somente conseguimos utilizar, desde o início, o glutaraldeido a $2 \%$ para a fixaçāo, no encéfalo correspondente à autópsia de número 629 . Retirado 6 horas após o óbito, permitiu-nos, entāo, processá-lo para a microscopia eletrônica de acordo com as normas modernas. A técnica de preparação destas amostras biológicas obedeceu às seguintes etapas: fixação, desidrataçāo, embebição e inclusão, corte e coloração ou contraste.

A técnica empregada constou de imersão do tecido na solução fixadora, na temperatura de $4{ }^{\circ} \mathrm{C}$, por $60 \mathrm{~min}$. A soluçāo fixadora era composta de $1 \mathrm{ml}$ de glutaraldeído a $2,5 \%, 5 \mathrm{ml}$ de cacodilato de sódio $0,02 \mathrm{M}, 4 \mathrm{ml}$ de água destilada; pH da solução 7,2 . Dando prosseguimento, lavou-se o material em água destilada, duas vezes, durante $10 \mathrm{~min}$. Com a finalidade de corar e de fixar o material, utilizamos o acetatu de uranila a 0,5\% em solução aquosa. Deixou-se o material nesta solução por $15 \mathrm{~min}$. Então, lavou-se uma última vez em água destilada, durante $10 \mathrm{~min}$. A fim de remover gradualmente a água livre do tecido fixado, preferimos usar o álcool etílico, na seguinte sequiência: álcool a 50\%, duas vezes, durante $5 \mathrm{~min}$; álcool a 70\%, duas vezes, durante $5 \mathrm{~min}$; álcool a 95\%, duas vezes, durante $10 \mathrm{~min}$; álcool a 100\%, três vezes, durante $10 \mathrm{~min}$; resina - emblocado em resina Polylite. Os sedimentos desidratados foram incluídos em cápsulas de gelatina mantidas a $60 \circ \mathrm{C}$ nor 48 horas. Antes de serem submetidos à ultramicrotomia, produziram-se pirâmides, utilizando-se o Pyramitome R LKB Bromma 11800. Os blocos foram cortados no ultramierótomo Reichert, modelo 570, com navalha de vidro previamente preparada em 'knife maker' da LKB, modelo 7800. De regra, trabalhamos com cortes na faixa de 60 a 90 nanômetros (600 


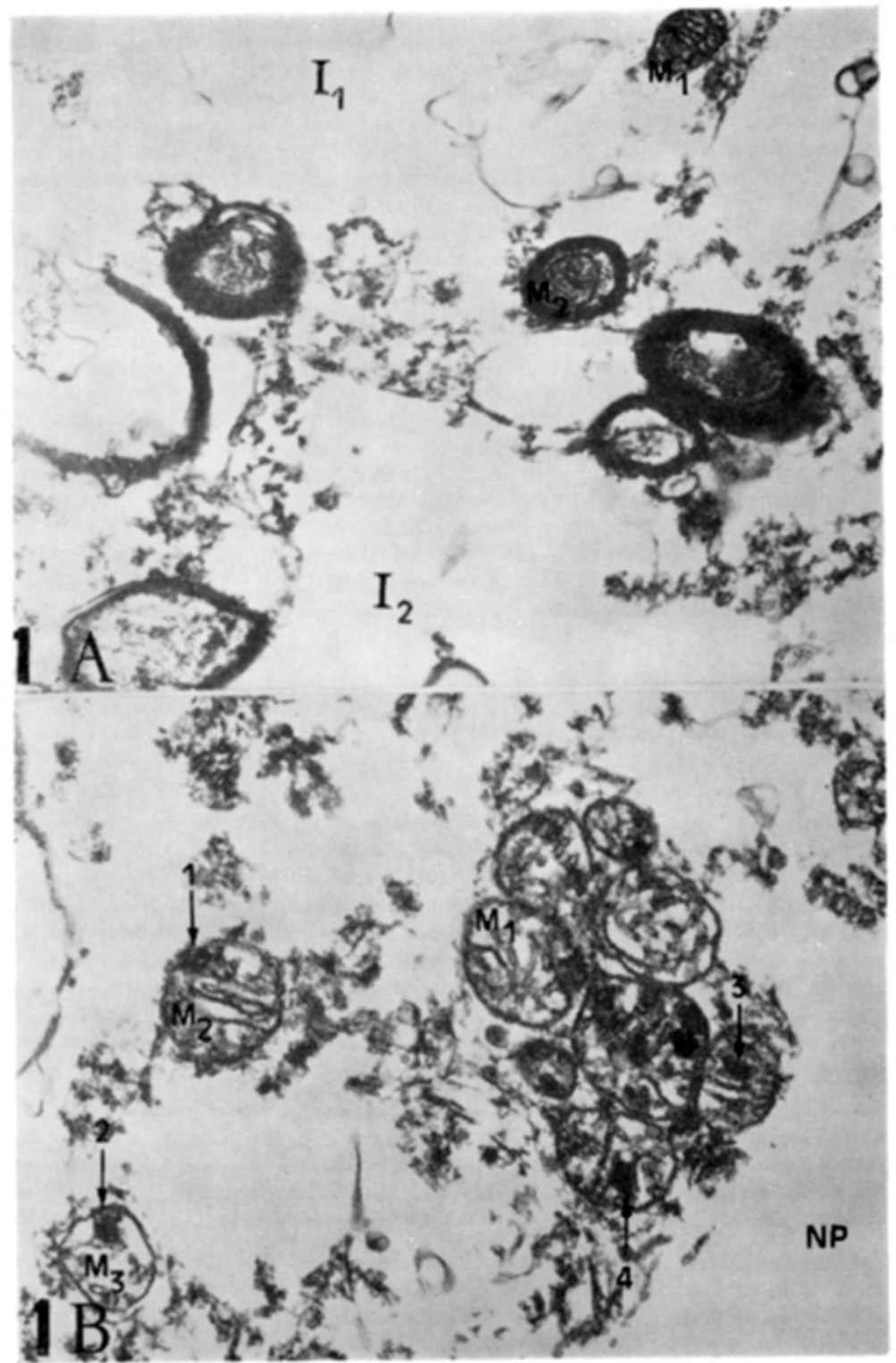

Fig. 1 - Eletronomicrografia. A e B (caso 2): Em A, córtex de lobo frontal evidenciando notável empobrecimento das fibras nervosas com alargamento do espaço intersticial $\left(I_{1}, I_{2}\right)$; desintegracão do neurópilo; volumosa mitocôndria $\left(M_{2}\right)$ ocupando quase todo o axônio; mitocôndria $\left(M_{1}\right)$ tumefeita com preservação de suas crístas (22000X). Em B, corte mesencefálico com aglomerado de mitocôndrias $\left(M_{1}, M_{2}, M_{3}\right)$ nas quais se evidenciam corpos arredondados elétron-densos (setas 1, 2, 3 e 4); nitido empobrecimento das fibras nervosas; neurópilo esgarçado; acentuado alargamento do espaço intersticial (38000 $\times)$. 


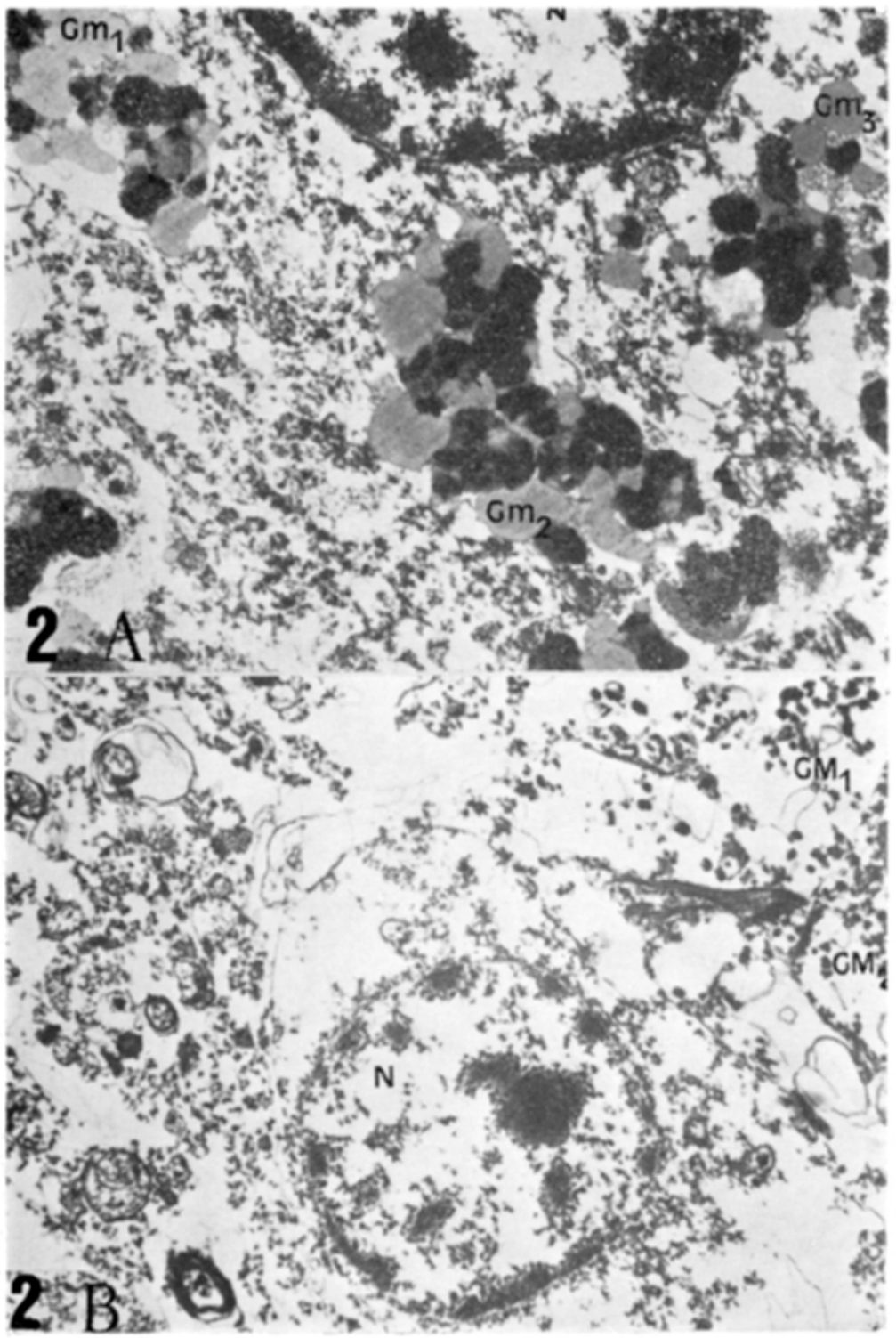

Fig. 2 - Eletronomicrografia. $A$ e B (caso 3): Em A, corte mesencefalico, vê-se pequeno neurónio pigmentado com granulos de melanina $\left(G_{m 1}, G_{m 2}, G_{m 3}\right)$; pobreza de fibras nervosas; aumento do espaco intersticial (18000×). Em $B$, corte mesencefálico, presença de célula glial; empobrecimento de fibras nervosas; granulos de melanina $\left(G_{m 1}, G_{m 2}\right)$ soltos no intersticio $(10000 \times)$. 


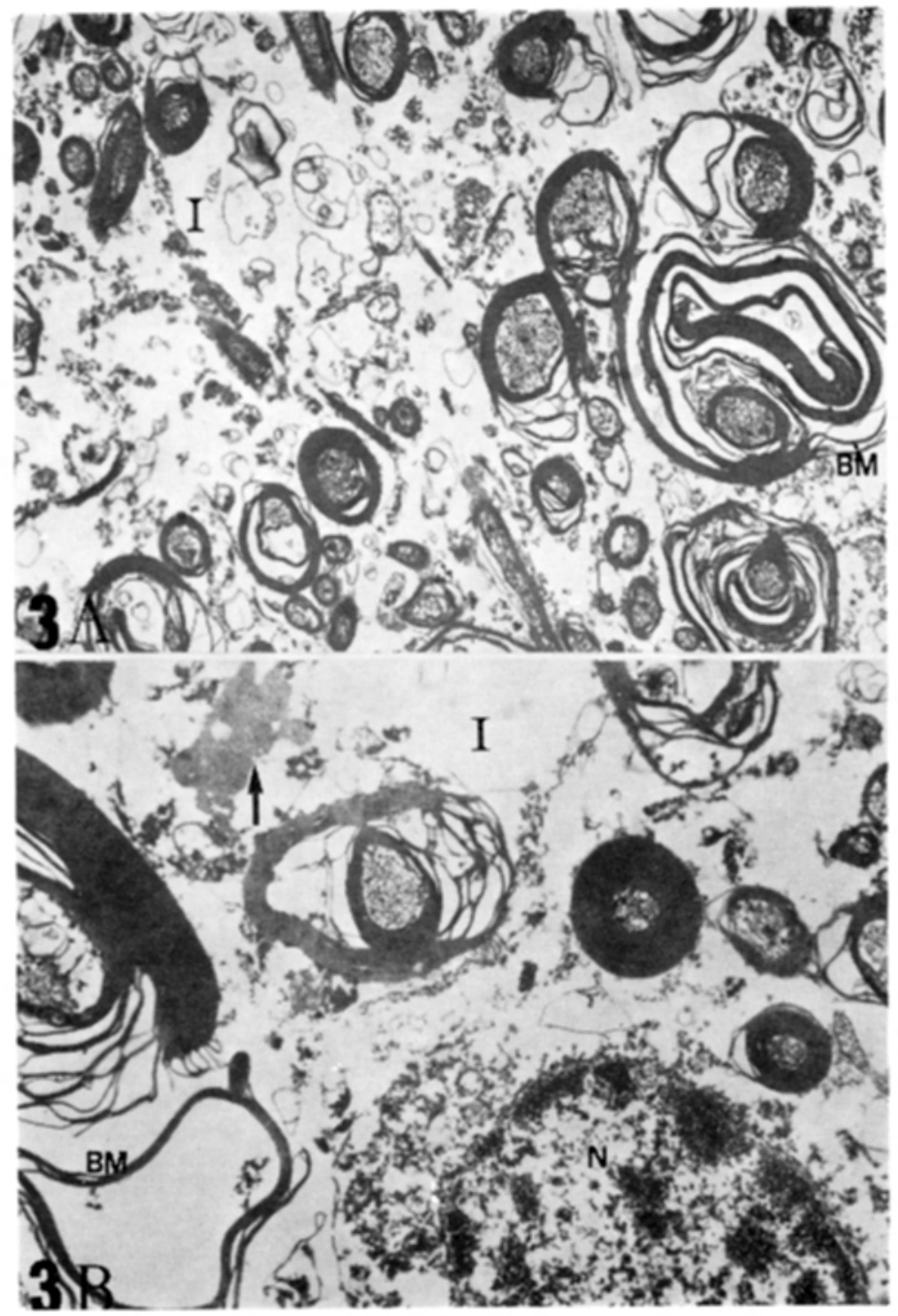

Fig. 3-Eletronomicrografia. A e B (caso 4): Em A, nivel mesencefálico, aumento do espaço intersticial (I); empobrecimento de fibras nervosas; alteraçóes na bainha de mielina (BM), conseqüências da fixaşão pelo formol $(6800 \times)$. Em B, alargamento do espaço intersticial (I); empobrecimento de fibras nervosas; núcleo (N) de célula glial bem conservado; bainha de mielina (BM) com artefatos de fixação; aglomerado de substancia amorfa (seta), extracelular, homogênea, de contorno ondulado $(12000 \times)$. 


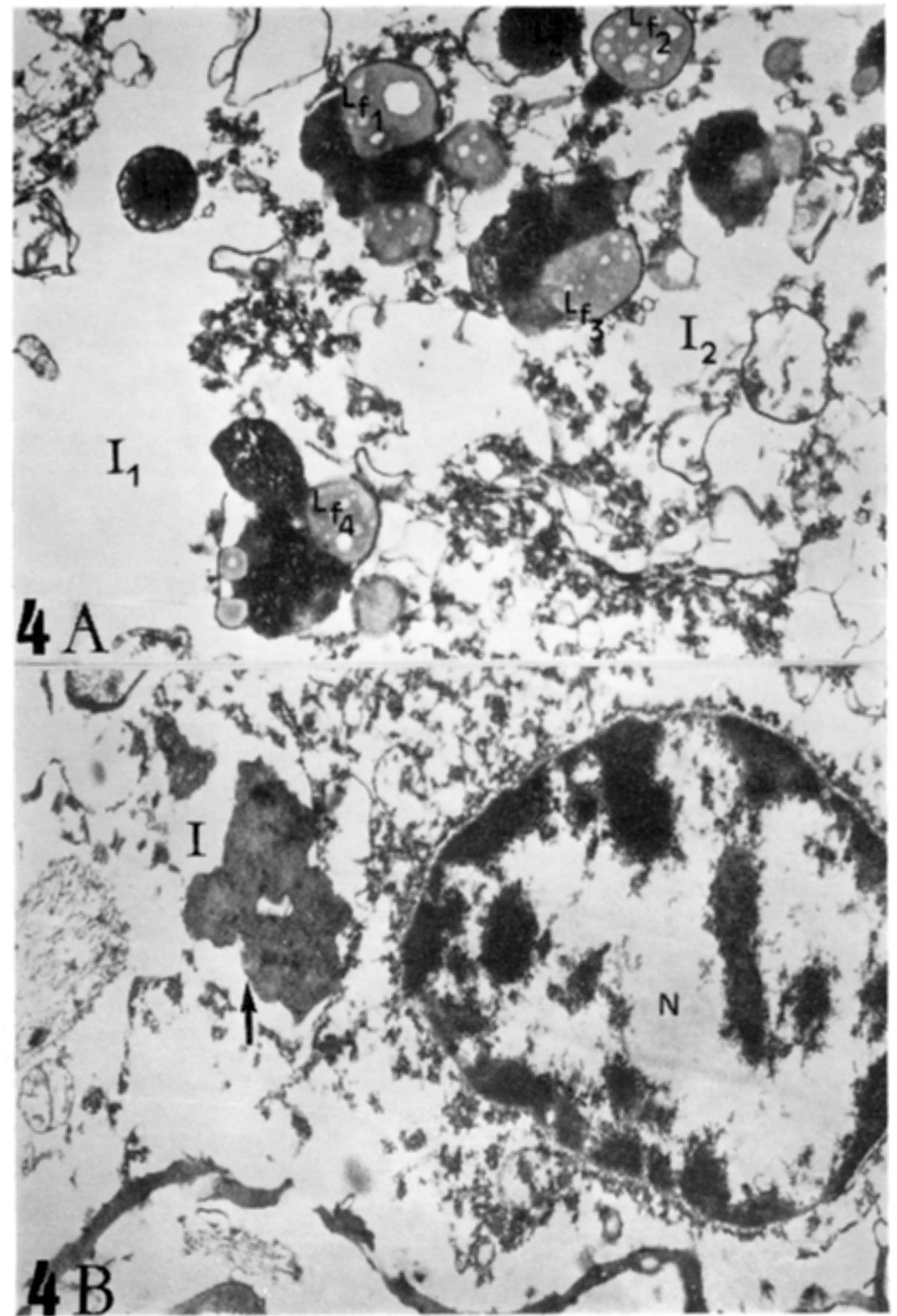

Fig. 4 - Eletronomicrografia. $A$ e $B$ (caso 5): Em A, mesencéfalo conservado e fixado em glutaraldéido a 2\%, mostra-se gnande destruição do neurópilo; extraordinário alargamento do espaco intersticial $\left(I_{1}, I_{2}\right)$; presença de lisossomas $\left(L_{1}, L_{2}\right)$ e de grânulos de lipofuscina $\left(L_{f 1}, L_{f 2}, L_{f 3}, L_{f_{4}}^{j}(38000 \times)\right.$. Em $B$, núcleo (N) celular bem conservado; citoplasma e organelas em desintegração; estrutura amorfa, aparentemente no interstício (I), irregular, elétron-diensa (seta) (12000×). 
a 900 A). Antes da coloração das amostras, estas foram lavadas com ácido nitrico a $1 \%$. em seguida, em água destilada e colocadas nas grades pelo método do 'mergulho'. Para aumentar o contraste das estruturas das amostras, os cortes foram impregnados com solução de acetato de uranila a $1 \%$, por $5 \mathrm{~min}$, lavados em álcool absoluto e impregnados, novamente, com citrato de chumbo de Reynold; a seguir, lavados em água com gotas de hidróxido de sódio e secos ao ar; prontas, procedeu-se ả análise ao microscópio de transmissảo Philips 301 (Philips Eidhoven Holland).

\section{RESULTADOS}

Preferimos dividir em três grupos (mais freqüentes, menos freqüentes e estruturas năo-identificadas) os resultados da análise dos encéfalos humanos, observados ao microscópio eletrônico de transmissāo, nas regióes frontal, mesencefálica e protuberancial.

As mais frequientes e, provavelmente, de maior significado, foram: empobrecimento de fibras nervosas; grande aumento do espaço intersticial; desintegração do neurópilo; tumefacão e degeneração das mitocôndrias, algumas com inclusões; tumefação das cisternas do retículo-endoplasmático; desintegração axonal e alteraçōes na bainha de mielina (Figs. $1,2,3$ e 4 ).

As menos frequientes: fragmentaçāo da membrana nuclear; formaçōes vesiculares de grande volume; desintegração das citomembranas do corpo neuronal; rotura das membranas dos dendritos; disposiçāo em forma đe 'meio-lua' da cromatina nuclear; profundas alteraçōes no cilindro-eixo com rotura de suas membranas e desintegração do citoplasma e das organelas nucleares.

As estruturas nāo-identificadas: corpúsculo granular fortemente elétron-denso cercado por halo claro; 'massa' ou corpúsculo granular com áreas compactas; corpos granulares grosseiros; formaçōes tubulares; aglomerado de substância amorfa no citoplasma, nas mitocôndrias e no espaco extracelular (Figs. 3B e 4B).

\section{COMENTARIOS}

Do nosso material analisado pelo microscópio eletrônico de transmissão, constam cinco encéfalos humanos. Destes, quatro são de pacientes parkinsonianos e um, de caso controle, falecido em consequência de edema cerebral. Os quatro primeiros materiais (autópsias de números $411,417,426 \mathrm{e} 428$ ) foram conservados, aproximadamente durante 20 anos, em formol a 10\%; o outro (autópsia de número 629), fixado em glutaraldeido a $2 \%$, desde o início. Apesar de os quatro primeiros materiais terem sofrido, também, o processamento em glutaraldeído a $2 \%$, devemos, a seguir, nos referir às possiveis e prováveis alteraçóes encontradas como sendo atribuidas à fixaçāo inicial pelo formol a $10 \%$.

$\mathrm{O}$ caso 1 (controle) serviu de modelo para traçar a orientação básica frente às alteraçōes que iriamos, provavelmente, encontrar nos encéfalos de parkinsonianos. Logo, a retração dos axônios no interior das fibras, as alterações da bainha de mielina, as mitocôndrias túrgidas, as distorções das citomembranas e a vacuolização dos axônios não foram valorizadas, sendo todas, presumivelmente, atribuídas à fixação pelo formol, ou mesmo ao edema cerebral gerado pela doença básica. Por outro lado, deve-se salientar a preservação ou a pouca alteração de certas estruturas igualmente com a mesma fixaçăo. Achamos, pois, de importância significativa para ulteriores conclusōes comparativas, a população de fibras nervosas mielinizadas com os axônios bem conservados, a maior concentração de fibras por unidade de superfície e a relativa integridade do neurópilo e do espaço intersticial, em que pese a mesma fixação pelo formol a $10 \%$.

O empobrecimento das fibras nervosas, o grande aumento do espaço intersticial, a desintegração do neurópilo e a tumefação e degeneração das mitocôndrias foram consideradas como as mais frequêentes alteraçōes encontradas nos quatro encéfalos de parkinsonianos. Com exceção das alteraçóes das mitocôndrias, que logo veremos, as demais ocorreram em todos os encéfalos de parkinsonianos, fato não observado no caso controle, o que torna dificil atribuj-las à fixação. Traduzem, em última análise, a perda neuronal crônica, ultimamente salientada por Barbeau 1-3, Mann e Yates 8 e Kondo 7. Entre as alteraçōes mitocondriais, afora tumefação e degeneração, desejamos salientar, em particular, o encontro de certos depósitos amorfos nos seus interiores (inclusōes mitocondriais). Estes merecem destaque, embora somente muito tempo depois tenhamos percebido que Forno 5 já os notificara no 'locus coeruleus' de pessoas de meia-idade e idosas, com ou sem parkinsonismo. Descreveram como inclusões nãomembranosas, amorfas, preenchendo a matriz mitocondrial. Na oportunidade, os autores suspeitaranı ser sua composição de fosfolipídios. Acrescente-se que estas inclusões 
não-membranosas e amorfas foram também por nós documentadas no interior dos axônios e no espaço intersticial (Fig. 3B), o que não consta nas observaçóes de Forno 5. A tumefação das cisternas do retículo-endoplasmático, a desintegração axonal e as alteraçóes na bainha de mielina foram atribuídas, mais facilmente, à fixação pelo fortnol.

A fragmentação da membrana nưclear, as formações vesiculosas de grande volume, a desintegração das citomembranas no corpo neuronal, a rotura da membrana dos dendritos, a disposição em forma de 'meia-lıa' da cromatina nuclear $\mathrm{e}$ as alteraçōes do cilindro-eixo com rotura das suas membranas, bem menos freqüentes, mesmo não tendo sido encontradas no caso controle, poderiam ser interpretadas, até que se prove o contrário, como artefatos de técnica.

As alteraçōes que se seguem, e que não conseguimos identificar, foram igualmente julgadas importantes: corpúsculo granular fortemente elétron-denso cercado por halo claro, 'massa' ou corpusculo granular com áreas compactas, corpúsculo redondo de dupla membrana, formações tubulares, grande depósito homogêneo com partículas disseminadas, partículas esféricas e os já citados aglomerados de substância amorfa nas mitocôndrias, no citoplasma e no espaço extracelular (Fig. 3B). Acreditamos, embora sem muita experiência, que estas ủltimas sejam inclusôes não-membranosas e amorfas, descritas por Forno 5 , em 1981, no 'locus coeruleus' de pessoas de meiaidade e idosas, parkinsonianas ou não, interpretadas como compostas por fosfolipídios. Como já nos referimos, no entanto, Forno 5 somente chamou a atenção para as inclusóes mitocondriais. Sendo sabidamente parcos os nossos conhecimentos atuais no tocante às alterações ultra-estruturais no parkinsonismo, estas estruturas, quando identificadas, poderão ser de alta relevância.

Quanto ao caso referente à autópsia de número 629 , gostaríamos de lembrar, representou o único processado desde o início com glutaraldeido a $2 \%$, conforme recomendan as modernas técnicas de microscopia eletrônica. O padrão eletronomicrográfico deste material não se mostrou, entretanto, superior aos demais fixados inicialmente com formaldeído; pelo contrário, apesar de o processamento correto se ter iniciado 6 horas após o óbito do paciente, a qualidade do material não se revelou gratificante. Conseqüentemente, algumas das alteraçōes observadas e atribuidas inicialmente à fixação pelo formol devem ficar, pelo menos por enquanto, como conjecturas.

Concluindo, as alteraçōes ultra-estruturais encefálicas na doença de Parkinson constaram, principalmente, de perda neuronal crônica, traduzidas por empobrecimento das fibras nervosas, grande aumento do espaço intersticial, desintegração do neurópilo e tumefaçāo e degeneração das mitocôndrias. A análise comparativa destas alterações năo nos permitiu atribuí-las à fixação pelo formol a $10 \%$; outras, sim. E, ainda, um conjunto de estruturas deixou de ser identificado. Por fim, observamos a presença de depósitos amorfos, parecendo tratar-se de inclusōes no interior das mitocôndrias, dos axônios, do citoplasma e do espaço intersticial.

\section{REFERENCIAS}

1. Barbeau A - Etiology of Parkinson's disease: research strategy neurology. Can J Neurol Sci 11:24, 1984 .

2. Barbeau A - Parkinson's disease: etiological considerations, In Yahr, MD (ed): The Busal Ganglia. Raven, New York, 1976, pg 281.

3. Barbeau A - Parkinson's disease: etiological considerations, Res Publ Assoc Res Nerv Ment Dis 55:281, 1976.

4. Duffy PE, Tennyson VM - Phase and electron microscopic observations of Lewy bodies and melanin granules in the substantia nigra and locus coerulcus in Parkinson's disease. $J$ Neuropath Exp Neurol 24:398, 1965.

5. Forno LS - Pathology of Parkinson's disease. In Marsden CD, Fahn S (eds): Movement Disorders. Butterworth, London, 1981, pg 25.

6. Forno LS, Norvilie RL - Ultrastructure of Lewy bodies in the stellate ganglion. Acta Neuropath $34: 183,1976$.

7. Kondo K - Epidemiological clues for the etiology of Parkinson's disease. Adv Neurol $40: 345,1984$.

8. Mann DMA, Yates PO - Pathogenesis of Parkinson's disease, Arch Neurol 39:545, 1982.

9. Roy S, Wolman L - Ultrastructural obgervations in the parkinsonism. J Path 99:39, 1969.

10. Watanabe I, Vachal E, Tomita $T$ - Dense core vesicles around the Lewy body in incidental Parkinson's diseuse: an electron microscopic study. Acta Neuropath 39:173, 1977. 